\title{
The treatment burden and families' rights
}

\author{
Trevor Jackson deputy editor, The BMJ
}

We hear much these days about how health systems and those who work in them are under unprecedented strain. In the United Kingdom, general practitioners are said to be feeling overwhelmed, hospital waiting lists are rising, and policy makers and the public face difficult questions about how to fund an NHS whose services are increasingly in demand. But as well as caregivers, patients-particularly those with multimorbidity - are feeling the demands made by healthcare systems. This is the burden of treatment, which Frances S Mair and Carl R May discuss in an editorial this week (doi:10.1136/ bmj.g6680).

As they write, "The burden continues to increase as healthcare systems shift an ever growing list of management responsibilities and tasks on to patients and their caregivers. This is real work, which requires considerable effort from patients, their caregivers, and their extended social networks." The burden can be more severe on patients from lower socioeconomic backgrounds. Patients who work several jobs, for example, may find it hard to "follow the requirements of multiple clinical guidelines" and "struggle to adhere to treatment recommendations." Other challenges include the expense of getting to clinic appointments and learning self management skills, such as coping with polypharmacy and giving yourself regular injections.

Assessing and documenting the burden of treatment could even become a key quality measure, say Mair and May, who have previously argued for "minimally disruptive medicine." But until reliable measures are available, they say that a simple question from the doctor may suffice: "Can you really do what I am asking you to do?"
Our essayist this week, Barbara Lewis, has thought so much about the effect that health systems can have on patients and their families that she drew up a bill of rights that has begun to transform care in the United States (doi:10.1136/bmj.g6022). After her sister, Joan, was admitted to hospital with low blood pressure and acute kidney and liver failure, Lewis spent two weeks by her bed in an intensive care unit and documented interactions with the healthcare team. After Joan's death, Lewis took the 44 pages of notes, "which included vital signs, prescriptions, test results, details of doctor and nurse visits," created Joan's family bill of rights, and emailed it to the head of the unit, who sent it to the hospital chief executive, who in turn sent it to the heads of the healthcare system.

Lewis says that although patients' bills of rights and responsibilities, outlining the expectations of patients, are posted throughout hospitals, "nowhere are there rights of families, who spend long hours at the bedsides of loved ones." Lewis's recommendations to staff include: "Don't carry on conversations as if you're in the cafeteria. Use your quiet voice at all times. Families hear all the gossip, confidential patient information, and inconsiderate remarks such as 'I'm just waiting for my two patients to die.",

The document became the "cornerstone" of the health system's training programme, and Lewis decided to devote the rest of her life to improving the experience of patients. As she says, "Isn't healthcare a team sport with patients and families involved?"

Cite this as: BMJ 2014;349:g6782

๑ BMJ Publishing Group Ltd 2014 